\title{
Microscopy in combination with image analysis for characterization of fishmeal material in aquafeed
}

\author{
Luciano Pinotti ${ }^{1}$, Matteo Ottoboni ${ }^{1}$, Valentina Caprarulo ${ }^{1}$, Carlotta Giromini ${ }^{1}$, Davide \\ Gottardo ${ }^{1}$, Federica Cheli ${ }^{1}$, Tom Fearn², Antonella Baldi ${ }^{1}$ \\ ${ }^{1}$ Dipartimento di Scienze Veterinarie per la Salute, la Produzione Animale e la Sicurezza \\ Alimentare (VESPA), Università degli Studi di Milano, Italy. \\ ${ }^{2}$ Department of Statistical Science, University College London (UCL), London, UK
}

Corresponding author: Dr. Matteo Ottoboni, VESPA, Università degli Studi di Milano, Via Celoria 10, 20134 Milano, Italy - Tel. +39 0250315742 - Fax +39 0250315746 - E-mail:

matteo.ottoboni@unimi.it

\begin{abstract}
The aim of this study was to investigate the use of microscopy in combination with image analysis (IA) measurements for the characterization of fish bone lacunae in aquafeedextracted material. For this purpose two experiments have been conducted.

In experiment (exp.) 1, six samples of fish meal based aquafeed were analyzed by the microscopic method, according to Annex VI of Regulation 152/2009. Sediment fractions of each sample were observed with a compound microscope at X40. Two hundred and fifty eight bone fragment lacunae images were recorded and processed through IA software. Accordingly, on each lacuna 30 geometric variables have been obtained and measured. The geometric variables have been grouped in two main families, namely size descriptors and derived shape descriptors.

In exp. 2 measurements obtained from 1081 bone lacunae (644 for mammals and 437 for poultry) acquired from 14 mammalian and 7 poultry samples have been merged with the aquafeed dataset (258 bone lacunae). Results obtained in exp. 1 indicated that nearly two thirds of the descriptors presented differences among the analyzed samples. Differences in observed values were not systematically distributed among the six samples. Nevertheless, in all analyzed samples features of lacunae have shown an overlap. By contrast the comparison of fish bone lacunae with avian and mammalian bone lacunae (exp. 2), has revealed a large gap between terrestrial and aquatic animals in the case of several descriptors (16 primary and 8 secondary descriptors). Therefore, it can be concluded that combining light microscopy and image analysis: (i) fish material in aquafeed appears quite homogenous in term of bone features; ii) fish material can be distinguished from avian and mammalian materials by selecting specific descriptors.
\end{abstract}

\section{Keywords}

Fishmeal, image analysis, microscopy, processed animal proteins (PAPs). 


\section{Introduction}

The recent revision of the feed ban rules (European Commission, 2013b), which reauthorized from 1 June 2013 processed animal proteins (PAPs) from non-ruminants for use as feed or feed ingredient in aquaculture, is a new scenario in both animal nutrition and feed analysis. In fact, reintroducing non-ruminant PAPs in feed for aquaculture represents a big challenge for the feed sector, since old and new analytical and characterization requirements need to be addressed. In the EU only two methods are allowed within the frame of official controls for the detection of animal proteins in feed, namely light microscopy and polymerase chain reaction (PCR), which delivers information on the species origin of the detected PAPs (Regulation (EC) No 152/2009; Regulation (EU) No 51/2013). Both methods have been validated for proper implementation of the feed ban. Light microscopy in combination with computer image analysis $(\mathrm{IA})$, which is based on the identification of bone particles or tissues in feedingstuffs, has been also proposed (Ottoboni et al., 2014; Pinotti et. al., 2013; van Raamsdonk et al., 2007). Findings in these studies have indicated that the use of the microscopic method in association with computer image analysis to identify the origin of PAPs appears promising, especially as a complementary method to the DNA-based ones. Other methods are also applied by the feed sector, such as immunoassays and near-infrared microscopy (NIRM) (Tena et al.,2014). In this respect, Tena and coworkers (2014) have recently investigated a near-infrared microscopy method using partial least squares discriminant analysis (PLS-DA) to differentiate between meat and bone meal and fishmeal. In this study the evaluation of the spectra confirmed the conclusions from former studies that demonstrated that the higher content of polyunsaturated fatty acids in fishmeal compared to meat and bone meal is an important factor for the differentiation of these groups.

However, most of these methods developed and implemented for PAPs identification have been focused on the feed ban for terrestrial animal (Veys et al., 2014), and therefore fish meal characterization, especially in microscopy, was limited and mainly descriptive. In the literature (Makowski et al., 2011) it is reported that lacunae in fish bone fragments can be elliptical or elongated, whereas they can be oval to elliptical in terrestrial animals. With respect to fish material, herring and sardine have elliptical or elongated lacunae with clearly visible canaliculae, with irregularly shaped bone fragments (Makowski et al., 2011; van Raamsdonk et al., 2012). Fish bones of cod and its relatives are normally parallel sided, and show nearly linear lacunae without visible canaliculae, orientated parallel to the sides of the bone fragment. However, several species of fish (e.g. tuna and salmon) have bone lacunae resembling those of land animals (van Raamsdonk et al., 2012) making difficult the discrimination from other animal classes.

In light of this, it is important to implement methods of fishmeal characterization

not only in the case of pure material, but also in practical conditions such as in aquafeed. This goal can be achieved in different ways, including the use of methods already developed and applied to terrestrial PAPs. Accordingly, the aim of this study was to investigate the use of microscopy in combination with image analysis measurements for the characterization of fish bone lacunae in aquafeed-extracted material.

\section{Material and methods}

\section{Experiment 1}

For this experiment, 6 samples of commercial compound fish feeds containing fish meal have been used.

Chemical analysis 
Samples have been analyzed for dry matter (DM), crude oils and fats (CF), neutral detergent fiber (NDF), crude protein (CP) and ash. Specifically, the DM of feeds was determined by an oven-drying method, at $130{ }^{\circ} \mathrm{C}$ for $2 \mathrm{~h}$, as proposed by the European Commission (Commission Regulation $N^{\circ} 152 / 2009$ ) and CF was determined by the Soxhlet method, with prior hydrolysis, as proposed by the European Commission (Commission Regulation $\mathrm{N}^{\circ}$ 152/2009). Neutral detergent fiber analysis was performed according to procedures of the AOAC (2005): method 2002.04, using an Ankom 220 fiber analyzer (Ankom ${ }^{\mathrm{TM}}$ technology, Fairport, NY, USA); Neutral detergent fiber was measured using heat stable amylase and expressed exclusive of residual ash (aNDFom). Crude protein (CP) content has been measured according to the Kjeldahl method (proc. 2001.11; AOAC, 2005), while ash has been measured by using a muffle furnace at $550^{\circ} \mathrm{C}$ (proc. 942.05; AOAC, 2005).

\section{Microscopy and Image Analysis}

For microscopy and image analysis, samples have been previously ground with mortar and pestle. Five grams of ground material were transferred into a separation funnel and treated with $50 \mathrm{ml}$ of tetrachloroethylene in order to obtain the sediment. The total sediment of each sample was dried. If the sediment consisted of many large particles it was sieved in two fractions according to the official procedure (European Commission, 2013a). Subsequently several microscopic slides for each sample were prepared with the sediment fraction using Norland Optical adhesive 65 as embedding agent as reported in the official protocol for the detection of animal particles in compound feed (European Commission, 2013a). After drying each sample was observed using a compound microscope (Olympus BX41; Tokyo, Japan), at several magnifications. In order to guarantee a randomized image acquisition, at least 40 bone fragment lacunae images were randomly acquired at X40 in each sample without any preselection. Specifically, sediment material originating from extracted feeds have been used for preparing at several slides for each sample. Using a digital camera (Retiga 2000R, Fast 1394, QImaging) and image analysis software (Image-Pro Plus 7.0; Media Cybernetics Inc., Rockville, MD, USA), a total of 258 bone fragment lacunae images at X40, have been collected from the 6 samples. Images were acquired according to Pinotti et al. (2013). After acquisition, each image was processed in order to obtain a monochrome mask for each lacuna, on which thirty geometric variables have been measured (Pinotti et al., 2013). All lacunae measurements were collected in Excel files and used for dataset assembly.According to Ottoboni et al. (2014) geometric variables have been grouped in two groups, namely: size descriptors and derived shape descriptors. The size descriptors, also termed as dimension (primary) descriptors, represent direct measurements on bone lacunae. By contrast, the derived shape parameters are constructed by combining the various size parameters so that the dimension units are cancelled out (Neal and Russ, 2012). Both groups of descriptors are listed in table 1 and 2.

\section{Tables 1 and 2}

\section{Experiment 2}

In this experiment results obtained in experiment 1 (fish bone lacunae present in commercial aquafeed materials) have been merged with data obtained from poultry and mammalian authentic samples, used in Pinotti et al., 2013. Specifically, measurements obtained from 1081 bone lacunae (644 for mammals and 437 for poultry), acquired from 14 mammalian and 7 poultry samples have been merged with the aquafeed dataset (258 bone lacunae).

\section{Statistical analysis}

In experiment 1, lacunae measurements for aquafeed samples 1 to 6 were analyzed using one-way analysis of variance (one-way ANOVA) in order to compare means of the 6 
samples (GLM procedure of SAS statistical software 9.3). The analysis has been performed using the following model:

$\mathrm{y}_{\mathrm{ij}}=\mu_{\mathrm{j}}+\varepsilon_{\mathrm{ij}}$

Where $y_{i j}$ are the observations (measurements), $\mu_{j}$ is the mean of the observations for the $j^{\text {th }}$ group (sample) and $\varepsilon_{i j}$ represents the within-sample random variability. Differences with $P$ values $<0.001$ were considered significant. Furthermore, in order to compare the size of lacunae and evaluate the overlap of the six within-sample distributions, boxplots of these distributions were examined. Accordingly, the BOXPLOT procedure (PROCBOXPLOT) was performed in order to display the mean, median, quartiles, minimum and maximum observations and outliers for each single sample. Data points whose distances from the interquartile range was greater than 1.5 times the size of the interquartile range were considered outliers and plotted separately.

In experiment 2, data obtained from fish material (258 lacunae) in aquafeed were compared with poultry and mammalian lacunae (644 for mammals and 437 for poultry) using the morphometric descriptors reported in Pinotti et al. (2013). The analysis has been performed following the same model used in experiment 1, where $\mathrm{y}_{\mathrm{ij}}$ are the observations (measurements), $\mu_{\mathrm{j}}$ is the mean of the observations for the $\mathrm{j}^{\text {th }}$ group (animal class) and $\varepsilon_{\mathrm{ij}}$ represents the random variability between measurements in the same animal class. Differences with $P$ values $<0.001$ were considered significant. As in experiment 1 the BOXPLOT procedure (PROCBOXPLOT procedure of SAS statistical software 9.3) was also performed.

\section{Results}

\section{Experiment 1}

Chemical compositions of the compound fish feeds used in the present experiment were homogenous in term of nutrient contents (data not shown).

The results obtained combining the microscopic method and image analysis for fish material characterization are reported in tables 3 and 4 . Of the 21 primary descriptors reported, 8 did not show any difference between samples. Specifically, Diameter mean, Radius max, Radius min, perimeter (different types) and Area polygon were comparable among the 6 samples. In the case of the other 13 descriptors of the same group, some significant $(P<0.001)$ differences between samples have been observed. When shape descriptors were considered, the situation did not change. All shape descriptors related to radius and diameter were not significant, while Aspect, Area/Box, Box $X / Y$, Perimeter ratio and Roundness2 were different $(P<0.001)$ among samples. Significant differences in observed values however, were not consistently distributed across different descriptors. Although there are some significant differences between means, the boxplots for all the variables showed very substantial overlaps between the distributions of measurements in the six samples. The boxplots for Axis major and Form factor presented in figures $1 \mathrm{~A}$ and $1 \mathrm{~B}$ are typical examples.

\section{Tables 3 and 4}

\section{Figures 1A and 1B}

\section{Experiment 2}

Comparisons between fish, mammalian and poultry materials are presented in figures 2 and 3 . For 17 of the 21 primary descriptors reported, there were significant differences in mean 
between fish and each of the terrestrial materials. Axis minor and Diameter mean did not differ significantly between fish and poultry materials; area and Area polygon did not differ significantly between fish and mammalian materials (Figure 2). Considering the shape descriptors, 8 of the 9 descriptors were significantly different in mean in the fish material compared with poultry and mammals (Figure 3); the only exception was the shape descriptor Box $X / Y$ whose mean did not differ significantly from those of either of the other materials.

\section{Figures 2 and 3.}

An analysis of the box plots showed overlap of distributions for some descriptors but good separation for others. When fish material was compared to mammalian and poultry materials, a substantial overlap of the distributions of the measurements was observed in the case of eleven morphometric descriptors. These were Area, Box X/Y, Axis minor, Diameter minor, Diameter mean, Radius minor, Size width, Area polygon, Feret minor and Convex area among the primary descriptors, and Perimeter ratio among the secondary ones. By contrast, in the case of the other nineteen descriptors very little overlap was observed. In more detail, among primary descriptors fish material showed very little overlap with land animal material for the following descriptors: Aspect, Area/Box, Axis major, Diameter max, Radius max, Perimeter, Size length, Perimeter2, Perimeter convex and Perimeter ellipse, Feret max, Feret mean. In the case of secondary descriptors, all except Perimeter ratio showed very little overlap between fish material and land animal materials. Specific examples are presented in figures 4A, 4B, 4C and 4D.

Figures 4A, 4B, 4C and 4D.

\section{Discussion}

As expected, aquafeed composition was quite homogeneous among the 6 samples considered in the present experiment. Although 18 of the 30 descriptors measured on fish lacunae showed significant differences in mean between the 6 samples (tables 3-4), the box plot analysis has shown a substantial overlap between the 6 within-sample distributions for compound fish feeds analyzed in experiment 1 . These findings may be linked to the homogeneity of the fishmeal used in aquafeed formulation (Ayadi et al., 2012). Indeed, fishmeal used in aquafeed production principally derives from pelagic fishing which is further treated in order to obtain few standardized meals for the market. In addition, most fishmeal comes from a few big producers, using fish coming from three macro regions, namely Latin America (Peru and Chile), Scandinavia (Denmark and Norway) and Iceland (FAO Globefish, 2014). This scenario may contribute to the homogeneous nature of fish meals used in compound formulation, alhough this is somewhat speculative. Aquaculture feeds are made with small pelagic forage fish, in part to produce farmed fish with levels of omega-3 long chain polyunsaturated fatty acids that are equivalent to those of their wild counterparts (Tacon and Metian, 2008). These forage fish come from a global supply that is expected to remain static or decrease over time (Tacon and Metian, 2008; Deutsch et al., 2007), while its features (in term of fish bone lacunae) seem to be quite stable. A different scenario can be represented by fisheries by-products from salmon. Van Raamsdonk and coworkers (2012) observed that, this fish species shows sometimes an appearance that looks like that of land animals. Specifically Salmon fragments show irregular oval lacunae and canaliculae might not be visible. Our research group (unpublished results) has also observed these features.

A further result obtained in the present experiment is a detailed characterization of fish material in aquafeed. Observed values for some specific descriptors such us those related to axis, length and size, diameter, and feret have indicated that fish bone lacunae in the analyzed samples were characterized by a very large length-width ratio. In the same way, 
Roundness 2, which is a derived shape descriptor, calculated combining area and Axis major, provides a further indication about fish material features. The overall mean of the shape descriptor Roundness 2 in the fish samples was close to zero (i.e. 0.13), whereas in the case of avian and mammalian material the absolute values were more than twice $(0.28$, and 0.36 in avian and mammalian, respectively). Roundness 2 has a value of 1.00 for an ideal circle or a "circle like" shape. By contrast smaller values indicate a greater departure from this ideal (Neal and Russ, 2012). Thus, the very low values observed in the present experiment in all the analyzed samples indicate elongated lacunae (high Axis major-Axis minor ratio), although a contribution from extended perimeters in fish lacunae cannot be excluded (see below). These findings imply a flattened elongated to oblong shape for fish lacunae. This is in line with other authors (Gizzi et al., 2003; van Raamsdonk et al., 2012) who have described fish bone lacunae as elongated with a clear fusiform net of canaliculae, although in several species lacunae are linear without visible canaliculae. In this respect, IA seems to support the narrative shape description of fish bone lacunae in the literature. One more interesting shape descriptor for fish lacunae is represented by Form factor. The overall mean of Form factor in the fish samples is 0.18 . Form factor is a shape descriptor based on measurements of area and perimeter; briefly, in shapes having identical areas the value of Form factor decreases as the apparent irregularity of the boundary and depth of indentations (and the length of the perimeter) increases. In this sense, fish bone lacunae seem to be star-shaped. Moreover, this numerical evidence is probably due to the presence of a fusiform net of canaliculae confirming the narrative description reported by Gizzi et al. (2003). Therefore combining these two shape descriptors it can be concluded that the fish bone lacunae analyzed in the present experiment, appeared elongated and/or star-shaped (Figure 6).

With regard to experiment 2, for the "length" descriptors (Axis major, Diameter max, Radius max, Size length, Box height, Feret max), values in fish were twice as big compared to terrestrials indicating that bone lacunae are significantly longer in fish than in terrestrial animals material. Moreover, boxplot analysis indicated that the distributions of these size descriptors in fish had very little overlap with those from the terrestrial animals, suggesting these specific descriptors as valid markers for fish and terrestrial particle identification/discrimination. Moving to shape descriptors, for several of them (Aspect, Radius ratio, Roundness, Form factor and Roundeness2) a large gap between fish and mammalian and avian material has been observed. For instance, both Radius ratio and Roundness 2 indicated that fish bone lacunae are more elongated than in terrestrial (mammalian and poultry) lacunae, which are oval to elliptical. Considering the descriptor formfactor, a big distance was observed between values recorded in fish and in land animal material. This suggests that the shape descriptors like Radius ratio, Formfactor and Roundness2 could represent valid markers for fish material identification.

\section{Conclusions}

This study has investigated the use of microscopy in combination with image analysis measurements for the characterization of fish bone lacunae in aquafeed-extracted material. The fish material isolated and analyzed from commercial aquafeed (experiment 1) was quite homogenous in term of bone lacunae features; several descriptors can provide specific indications of fish bone lacunae shape. Both size and shape descriptors indicate that fish bone lacunae are elongated confirming narrative description reported in literature. The comparison with avian and mammalian materials (experiment 2) showed that fish meals can be efficiently distinguished from terrestrial materials by selecting specific descriptors, namely 
Radius ratio, Form factor and Roundness2 . Nevertheless, a larger dataset will be needed for an exhaustive evaluation.

\section{References}

1. AOAC, 2005. Association of Official Analytical Chemists. Official Methods of Analysis. 18th ed. AOAC Int, Gaithersburg, MD, USA.

2. Ayadi F.Y., Rosentrater K.A. and Muthukumarappan K. 2012. Alternative Protein Sources for Aquaculture Feeds. Journal of aquaculture feed science and nutrition. 4 (1): 1-26.

3. Deutsch, L., Gräslund, S., Folke, C., Troell, M., Huitric, M., Kautsky, N., \& Lebel, L. 2007. Feeding aquaculture growth through globalization; exploitation of marine ecosystems for fishmeal. Glob Environ Chang 17:238-49.

4. European Commission, 2009. Regulation No. 152/2009 of 27 January 2009 laying down the methods of sampling and analysis for the official control of feed. In: Official Journal, L54, 26/02/2009 pp 1-130.

5. European Commission, 2013a. Regulation No. 51/2013 of 16 January 2013 amending Regulation No 152/2009 as regards the methods of analysis for the determination of constituents of animal origin for the official control of feed. In: Official Journal, L 20, 23/01/2013 pp 33-43.

6. European Commission, 2013b. Regulation No. 56/2013 of 16 January 2013 amending Annexes I and IV to Regulation No 999/2001 laying down rules for the prevention, control and eradication of certain transmissible spongiform encephalopathies. In: Official Journal, L21, 24/01/2013 pp 3-16.

7. FAO Globefish. 2014. Fishmeal and Fish Oil - September 2014. http://www.globefish.org/fishmeal-and-fish-oil-september-2014.html

8. Gizzi G., Van Raamsdonk L.W.D., Baeten V., Murray I., Berben G., Bambilla G., von Holst C. 2003. An overview of tests for animal tissues in feeds applied in response to public health concerns regarding bovine spongiform encephalopathy. Rev Sci Tech. 22(1):311-31.

9. Makowski J., Vary N., McCurtcheon M., Veys P., 2011. Microscopic analysis of agricultural products, 4th edition. Urbana, USA. AOCS Press.

10. Neal F.B. \& Russ J.C. 2012. Measuring shape. CRC Press, Boca Raton, FL, USA.

11. Ottoboni M., Cheli F., Amato G., Marchis G., Brusa B., Abete M.C., Pinotti L. 2014. Microscopy and image analysis based approaches for the species-specific identification of bovine and swine bone containing material. Italian Journal of Animal Science, 13:3187.

12. Pinotti L., Fearn T., Gulalp S., Campagnoli A., Ottoboni M., Baldi A., Cheli F., Savoini G., Dell'Orto V., 2013. Computer image analysis: an additional tool for the identification of processed poultry and mammal protein containing bones, Food Additives \& Contaminants: Part A http://dx.doi.org/10.1080/19440049.2013.821715/.

13. Tacon A. and Metian M. 2008.Global overview on the use of fish meal and fish oil in industrially compounded aquafeeds: trends and future prospects. Aquaculture 285(1-4):146-58.

14. Tena N., Fernández Pierna J.A., Boix A., Baeten V, von Holst C. 2014. Differentiation of meat and bone meal from fishmeal by near-infrared spectroscopy: Extension of scope to defatted samples. Food Control, 43, 155-162

15. Van Raamsdonk L. W. D., Von Holst C., Baeten V., Berben G., Boix A., \& De Jong J. 2007. New developments in the detection and identification of processed animal proteins in feeds. Animal Feed Science and Technology, 133(1), 63-83. 
16.van Raamsdonk L.W.D., Pinotti L., Veys P., Campagnoli A., Paltanin C., Belinchon C., Jørgensen J.S. 2012. Markers for microscopic detection. In:, Jørgensen J.S. and Baeten V. Detection, identification and quantification of processed animal proteins in feedingstuffs, Namur, Belgique. Les Éditions namuroises.

17. Veys P., Baeten V., Fumière O., Lecrenier M.C., Berben G. 2014. EURL-AP inquiry on PCR analyses performed on feed or feed material for aquaculture in the European Union for the second halfyear of 2013. Eurl-ap report, may. (http://eurl.craw.eu/img/page/other/EURL-

AP\%20inquiry\%20report\%20PCR\%200n\%20fishfeed\%20FINAL.pdf) 
Table 1: Size / primary descriptors

\begin{tabular}{|c|c|c|}
\hline Variable & Unit & Description \\
\hline Area & $\mu \mathrm{m}^{2}$ & $\begin{array}{l}\text { Area of the object, includes area of the hole if 'Fill Holes' is turned } \\
\text { on }\end{array}$ \\
\hline Axis major & $\mu \mathrm{m}$ & Length of major axis of ellipse \\
\hline Axis minor & $\mu \mathrm{m}$ & Length of minor axis of ellipse \\
\hline Diameter max & $\mu \mathrm{m}$ & $\begin{array}{l}\text { Length of longest line joining two points of the object's outline and } \\
\text { passing through the centroid }\end{array}$ \\
\hline Diameter min & $\mu \mathrm{m}$ & $\begin{array}{l}\text { Length of shortest line joining two points of the object's outline and } \\
\text { passing through the centroid }\end{array}$ \\
\hline Diameter mean & $\mu \mathrm{m}$ & $\begin{array}{l}\text { Average length of diameters measured at } 2 \text { degree intervals and } \\
\text { passing through the object's centroid }\end{array}$ \\
\hline Radius max & $\mu \mathrm{m}$ & Maximum distance between object's centroid and outline \\
\hline Radius min & $\mu \mathrm{m}$ & Minimum distance between object's centroid and outline \\
\hline Perimeter & $\mu \mathrm{m}$ & $\begin{array}{l}\text { Length of the object's outline. More accurate than previous version. } \\
\text { Old version now called Perimeter2 }\end{array}$ \\
\hline Size (length) & $\mu \mathrm{m}$ & Feret diameter (i.e. caliper length) along major axis of object \\
\hline Size (width) & $\mu \mathrm{m}$ & Feret diameter (i.e. caliper length) along minor axis of object \\
\hline Perimeter 2 & $\mu \mathrm{m}$ & $\begin{array}{l}\text { Chain code length of the outline. Also includes any outlines of holes. } \\
\text { Faster but less accurate than Perimeter }\end{array}$ \\
\hline $\begin{array}{l}\text { Perimeter } \\
\text { (convex) }\end{array}$ & $\mu \mathrm{m}$ & Perimeter of the convex outline of the object \\
\hline $\begin{array}{l}\text { Perimeter } \\
\text { (ellipse) }\end{array}$ & $\mu \mathrm{m}$ & Perimeter of the equivalent ellipse \\
\hline Polygon area & $\mu \mathrm{m}^{2}$ & $\begin{array}{l}\text { Area included in the polygon defining the object's outline. Same } \\
\text { polygon as that used for Perimeter }\end{array}$ \\
\hline Box Width & $\mu \mathrm{m}$ & Width of the object's bounding box \\
\hline Box Height & $\mu \mathrm{m}$ & Height of the object's bounding box \\
\hline Min feret & $\mu \mathrm{m}$ & Smallest caliper (feret) length \\
\hline Max feret & $\mu \mathrm{m}$ & Longest caliper (feret) length \\
\hline Feret mean & $\mu \mathrm{m}$ & Average caliper (feret) length \\
\hline Convex area & $\mu \mathrm{m}^{2}$ & Area of a polygon which has major axis and minor Axis for sides \\
\hline
\end{tabular}


Table 2: Shape / derived descriptors

\begin{tabular}{|c|c|}
\hline Variable & Description \\
\hline Aspect & Ratio between major axis and minor axis of the ellipse equivalent to object \\
\hline Area/Box & Ratio between area of object and area of its bounding box \\
\hline Box $X / Y$ & Ratio between width and height of object's bounding box \\
\hline Radius ratio & Ratio between max radius and min radius \\
\hline Roundness & $\begin{array}{l}\left.\text { (Perimeter }{ }^{2}\right) /(4 \pi \text { Area). Uses 'Perimeter2' and 'Area' by default. Select } \\
\text { 'Perimeter' and 'Area' for more accurate Roundness }\end{array}$ \\
\hline Perimeter ratio & Ratio of convex perimeter to perimeter \\
\hline Form factor & $4 \pi$ Area/Perimeter ${ }^{2}$ \\
\hline Roundness 2 & 4Area/mAxis major ${ }^{2}$ \\
\hline Solidity & Area/Convex area \\
\hline
\end{tabular}


Table 3: Results size descriptors in experiment 1

\begin{tabular}{|c|c|c|c|c|c|c|c|c|c|c|c|c|c|}
\hline & & \multicolumn{2}{|c|}{ Sample 1} & \multicolumn{2}{|c|}{ Sample 2} & \multicolumn{2}{|c|}{ Sample 3} & \multicolumn{2}{|c|}{ Sample 4} & \multicolumn{2}{|c|}{ Sample 5} & \multicolumn{2}{|c|}{ Sample6 } \\
\hline & unit & mean & SE & mean & SE & mean & SE & mean & SE & mean & SE & mean & SE \\
\hline Area & $\mu \mathrm{m}^{2}$ & $107.1 \mathrm{a}$ & 4.51 & $85.8 b$ & 4.37 & 104.2 & 4.51 & 97.2 & 5.68 & 98.2 & 4.90 & 104.8 & 4.33 \\
\hline Axis major & $\mu \mathrm{m}$ & 33.5 & 1.17 & 32.3 & 1.13 & 30.1 & 1.17 & $28.8 \mathrm{a}$ & 1.47 & 31.9 & 1.27 & $35.0 \mathrm{~b}$ & 1.12 \\
\hline Axis minor & $\mu \mathrm{m}$ & 4.6 & 0.18 & $3.9 \mathrm{a}$ & 0.17 & $5.2 b$ & 0.18 & 4.8 & 0.23 & 4.6 & 0.20 & 4.6 & 0.17 \\
\hline Diameter max & $\mu \mathrm{m}$ & 36.3 & 1.34 & 35.6 & 1.30 & 34.7 & 1.34 & $31.5 a$ & 1.69 & 35.5 & 1.45 & $39.0 b$ & 1.28 \\
\hline Diameter min & $\mu \mathrm{m}$ & 4.1 & 0.17 & $3.6 a$ & 0.16 & $4.5 b$ & 0.17 & 4.3 & 0.21 & 4.0 & 0.18 & 3.9 & 0.16 \\
\hline Diameter mean & $\mu \mathrm{m}$ & 10.6 & 0.21 & 9.9 & 0.21 & 10.5 & 0.21 & 10.2 & 0.27 & 10.4 & 0.23 & 10.7 & 0.20 \\
\hline Radius max & $\mu \mathrm{m}$ & 20.0 & 0.75 & 19.6 & 0.72 & 19.2 & 0.75 & 17.8 & 0.94 & 19.9 & 0.81 & 21.7 & 0.72 \\
\hline Radius min & $\mu \mathrm{m}$ & 1.6 & 0.09 & 1.4 & 0.09 & 1.8 & 0.09 & 1.7 & 0.12 & 1.6 & 0.10 & 1.5 & 0.09 \\
\hline Perimeter & $\mu \mathrm{m}$ & 85.8 & 3.61 & 81.7 & 3.50 & 87.9 & 3.61 & 79.2 & 4.55 & 87.9 & 3.92 & 93.8 & 3.47 \\
\hline Size length & $\mu \mathrm{m}$ & 37.1 & 1.33 & 36.7 & 1.29 & 35.5 & 1.33 & $32.3 a$ & 1.67 & 36.5 & 1.44 & $40.3 b$ & 1.27 \\
\hline Size width & $\mu \mathrm{m}$ & 6.3 & 0.34 & $5.2 a$ & 0.33 & $7.7 \mathrm{~b}$ & 0.34 & 6.9 & 0.43 & 6.5 & 0.37 & 6.7 & 0.33 \\
\hline Perimeter 2 & $\mu \mathrm{m}$ & 93.7 & 4.22 & 88.6 & 4.09 & 96.5 & 4.22 & 85.8 & 5.31 & 98.0 & 4.58 & 104.8 & 4.05 \\
\hline Perimeter convex & $\mu \mathrm{m}$ & 77.4 & 2.70 & 75.5 & 2.61 & 74.7 & 2.70 & 68.3 & 3.40 & 76.3 & 2.93 & 84.0 & 2.59 \\
\hline Perimeter ellipse & $\mu \mathrm{m}$ & 68.9 & 2.29 & 66.1 & 2.22 & 62.7 & 2.29 & 59.9 & 2.88 & 65.7 & 2.49 & 71.9 & 2.20 \\
\hline Area polygon & $\mu \mathrm{m}^{2}$ & 101.9 & 4.35 & 80.6 & 4.22 & 99.0 & 4.35 & 92.0 & 5.48 & 93.2 & 4.73 & 99.9 & 4.18 \\
\hline Box width & $\mu \mathrm{m}$ & $31.3 a c$ & 1.63 & 24.9 & 1.58 & $22.1 b c$ & 1.63 & 23.0 & 2.06 & $29.5 c$ & 1.77 & $21.5 b$ & 1.57 \\
\hline Box height & $\mu \mathrm{m}$ & $18.9 a$ & 1.69 & $25.2 a b$ & 1.64 & $24.8 \mathrm{ab}$ & 1.69 & $20.5 a$ & 2.13 & $20.6 a$ & 1.84 & $31.4 b$ & 1.62 \\
\hline Feret min & $\mu \mathrm{m}$ & 6.3 & 0.32 & $5.2 \mathrm{a}$ & 0.31 & $7.6 \mathrm{~b}$ & 0.32 & 6.7 & 0.41 & 6.5 & 0.35 & $6.7 \mathrm{~b}$ & 0.31 \\
\hline Feret max & $\mu \mathrm{m}$ & 37.1 & 1.33 & 36.7 & 1.28 & 35.5 & 1.33 & $32.3 a$ & 1.67 & 36.6 & 1.44 & $40.3 b$ & 1.27 \\
\hline Feret mean & $\mu \mathrm{m}$ & 24.7 & 0.86 & 24.1 & 0.83 & 23.9 & 0.86 & $21.8 a$ & 1.08 & 24.4 & 0.93 & $26.8 b$ & 0.82 \\
\hline Convex area & $\mu \mathrm{m}^{2}$ & 155.2 & 7.33 & $123.8 a$ & 7.10 & 155.0 & 7.33 & 139.0 & 9.23 & 145.6 & 7.96 & $158.8 b$ & 7.03 \\
\hline
\end{tabular}

SE, standard error of means; Different letters $(a, b, c)$ indicate statistical difference $(\mathrm{P}<0.001)$ within the same line.

Table 4 Results shape descriptors in experiment 1

\begin{tabular}{|l|r|r|r|r|r|r|r|r|r|r|r|r|}
\hline & \multicolumn{2}{|c|}{ Sample 1 } & \multicolumn{2}{|c|}{ Sample 2 } & \multicolumn{2}{|c|}{ Sample 3 } & \multicolumn{2}{|r|}{ Sample 4 } & \multicolumn{2}{|r|}{ Sample 5 } & \multicolumn{2}{|r|}{ Sample 6 } \\
\hline & mean & SE & mean & SE & mean & SE & mean & SE & mean & SE & mean & SE \\
\hline Aspect & 7.61 & 0.41 & $9.00 \mathrm{a}$ & 0.40 & $6.18 \mathrm{~b}$ & 0.41 & $6.41 \mathrm{~b}$ & 0.51 & 7.46 & 0.44 & 8.11 & 0.39 \\
\hline Area/Box & 0.23 & 0.02 & $0.18 \mathrm{a}$ & 0.02 & $0.27 \mathrm{~b}$ & 0.02 & $0.28 \mathrm{~b}$ & 0.02 & 0.22 & 0.02 & 0.23 & 0.02 \\
\hline Box X/Y & $2.13 \mathrm{a}$ & 0.19 & $1.13 \mathrm{~b}$ & 0.19 & 1.38 & 0.19 & 1.42 & 0.25 & 1.63 & 0.22 & $1.05 \mathrm{~b}$ & 0.18 \\
\hline Radius ratio & 14.98 & 1.34 & 16.01 & 1.32 & 12.93 & 1.34 & 12.20 & 1.69 & 14.49 & 1.48 & 18.60 & 1.30 \\
\hline Roundness & 6.08 & 0.45 & 7.28 & 0.43 & 6.59 & 0.45 & 5.99 & 0.56 & 7.21 & 0.49 & 7.60 & 0.43 \\
\hline Perimeter Ratio & 0.90 & 0.01 & $0.92 \mathrm{a}$ & 0.01 & $0.86 \mathrm{~b}$ & 0.01 & 0.87 & 0.01 & 0.88 & 0.01 & 0.90 & 0.01 \\
\hline Form factor & 0.20 & 0.01 & 0.17 & 0.01 & 0.19 & 0.00 & 0.20 & 0.01 & 0.19 & 0.01 & 0.17 & 0.01 \\
\hline Roundeness 2 & 0.13 & 0.01 & $0.11 \mathrm{a}$ & 0.01 & $0.16 \mathrm{~b}$ & 0.01 & $0.15 \mathrm{bc}$ & 0.01 & 0.14 & 0.01 & $0.12 \mathrm{ac}$ & 0.01 \\
\hline Solidity & 0.70 & 0.01 & 0.70 & 0.01 & 0.68 & 0.01 & 0.70 & 0.01 & 0.69 & 0.01 & 0.67 & 0.01 \\
\hline
\end{tabular}

$\mathrm{SE}$, standard error; Different letters $(\mathrm{a}, \mathrm{b}, \mathrm{c})$ indicate statistical difference $(\mathrm{P}<0.001)$ within the same line. 
Figure 1. Box-plots displaying mean, median, quartiles, minimum and maximum observations and outliers for (A) Axis major and (B) Form factor values measured in samples 1 to 6 in experiment 1 .

Figure 2. Graphic representation of means and standard error (SE) by class of the size descriptors measured in experiment $2 . \mathrm{AVI}=$ avian; $\mathrm{FISH}=$ fish; $\mathrm{MAM}=$ mammals; $(\mathrm{x} 10)=$ measured value are multiplied by 10 . The means within morphometric descriptors with different letters $(a, b, c)$ differ significantly $(P<0.001)$.

Figure 3. Graphic representation of means and standard error (SE) by class of the shape descriptors measured in experiment 2 . AVI = avian; FISH = fish; MAM = mammals; $(x 10)=$ measured value are multiplied by 10 . The means within morphometric descriptors with different letters $(a, b, c)$ differ significantly $(P<0.001)$.

Figure 4. Box plots displaying mean, median, quartiles, minimum and maximum observations and outliers for (A) Axis major, (B) Radius ratio, (C) Form factor and (D) Roundness2 values measured in avian, fish and mammalian samples in experiment 2. AVI = avian; FISH = fish; MAM = mammals.

Figure 5. Examples of monochrome mask obtained using the image analysis software (Image-Pro Plus 7.0; Media Cybernetics Inc., Rockville, MD, USA) from fish bone lacunae. 
Figure 1
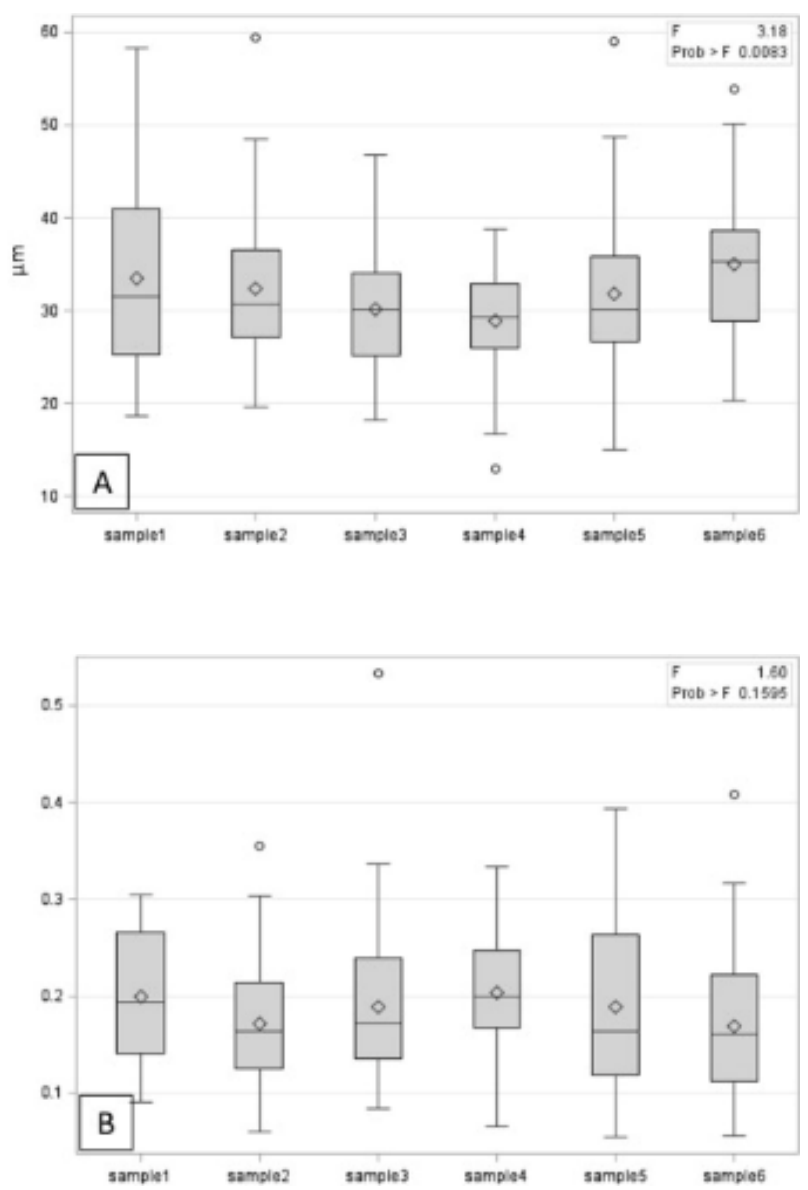

Figure 2

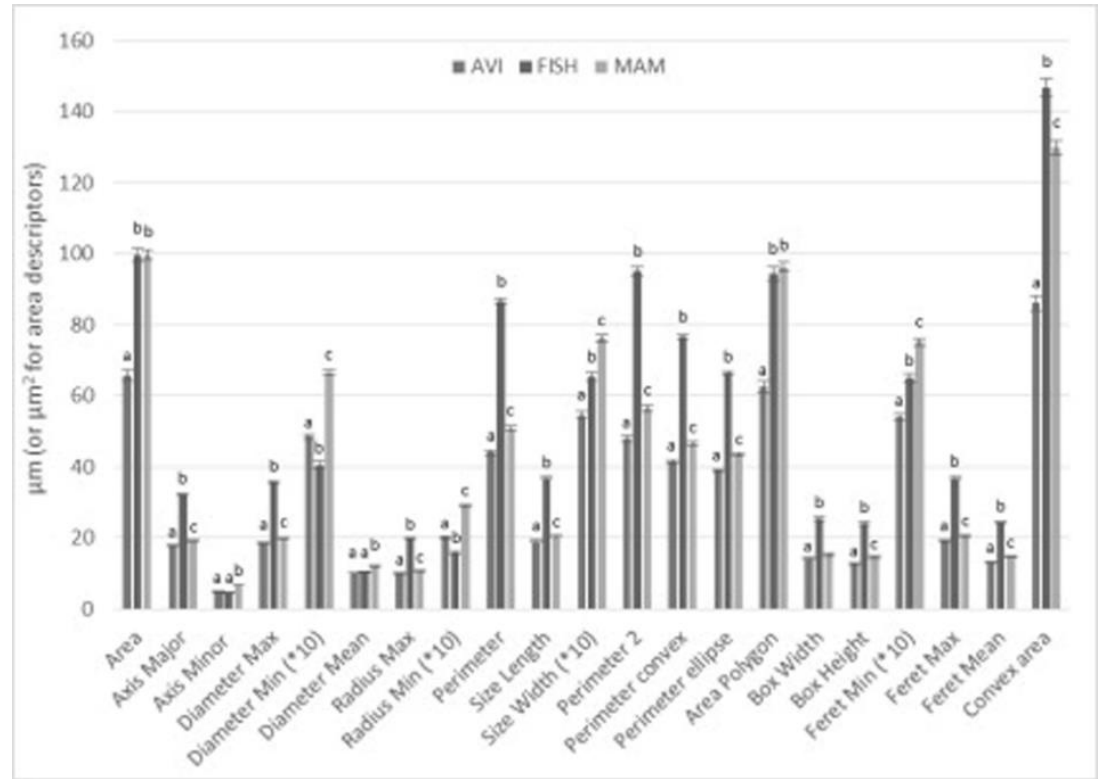


Figure 3

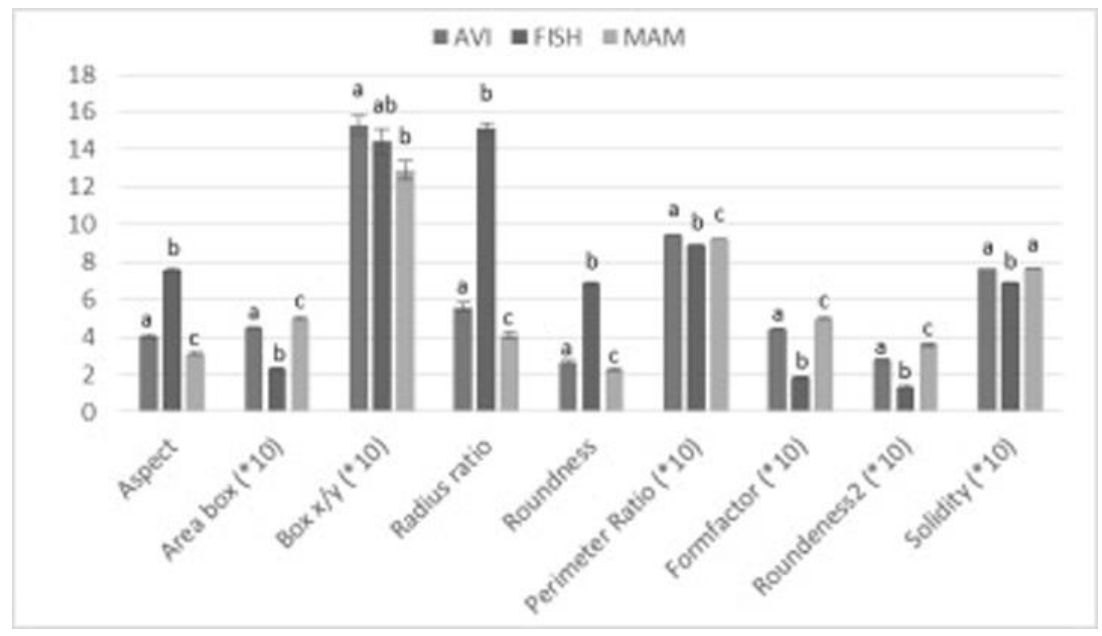

Figure 4
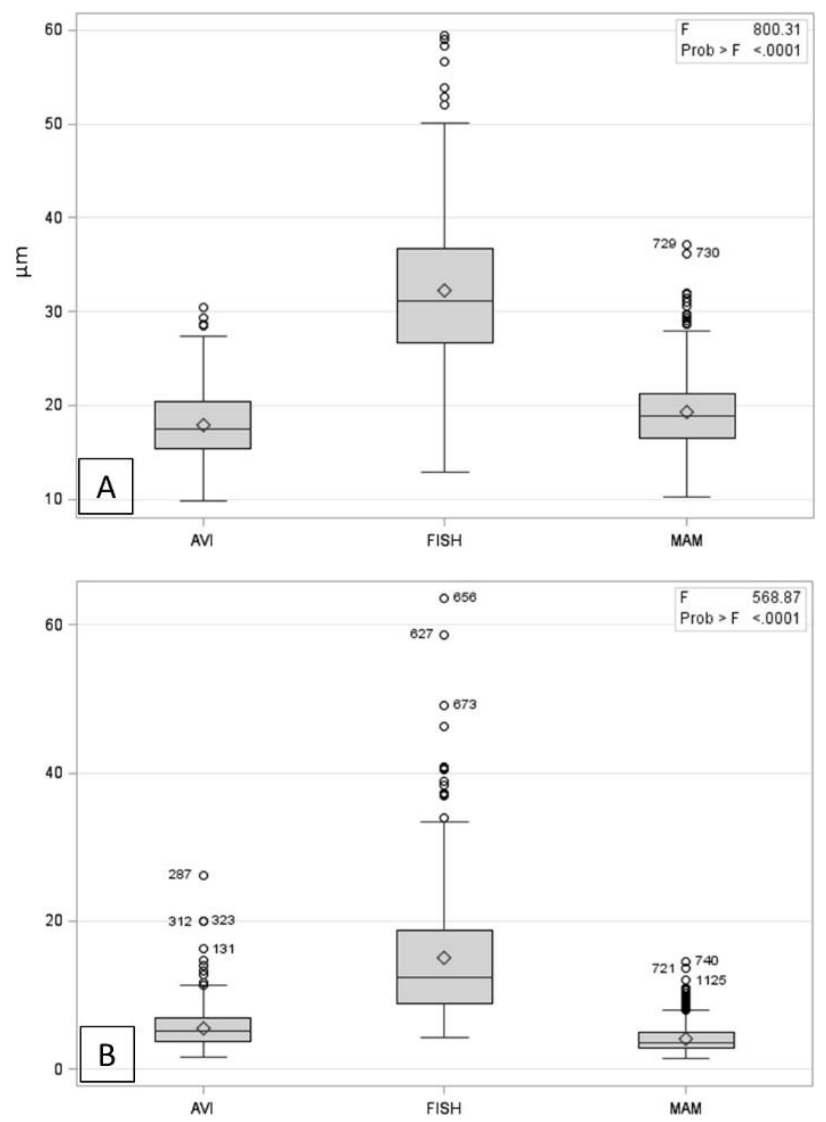

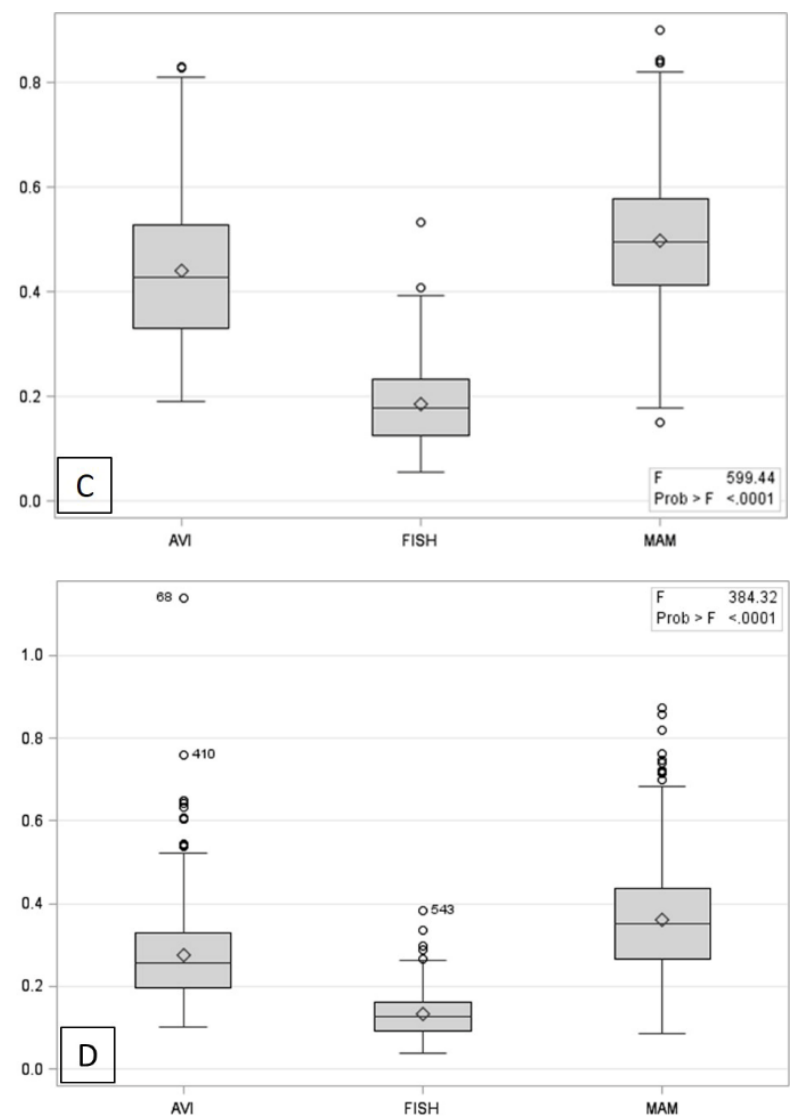

Figure 5

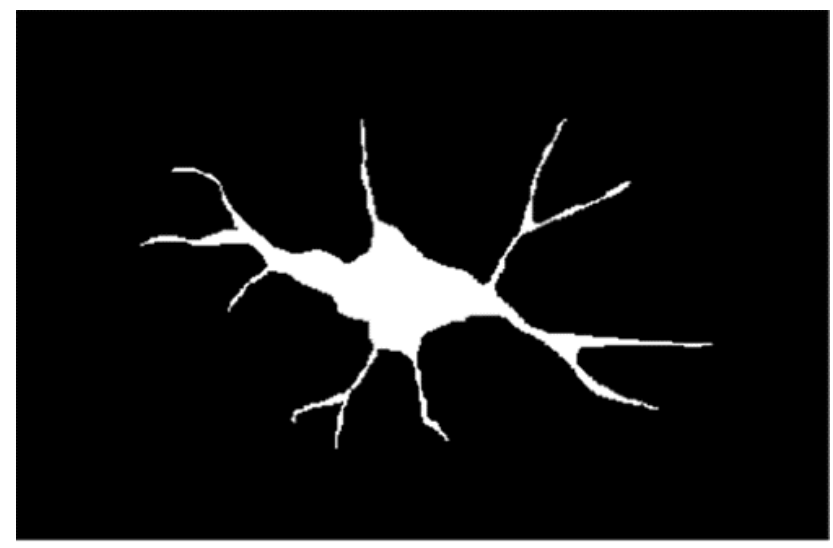

